\title{
The feeding route (enteral or parenteral) affects the plasma response of the dipetide Ala-GIn and the amino acids glutamine, citrulline and arginine, with the administration of Ala-GIn in preoperative patients
}

\author{
Gerdien C. Melis ${ }^{1}$, Petra G. Boelens ${ }^{1}$, Joost R. M. van der Sijp ${ }^{1}$, Theodora Popovici ${ }^{2}$, Jean-Pascal De Bandt ${ }^{2}$, \\ Luc Cynober ${ }^{2}$ and Paul A. M. van Leeuwen ${ }^{1 *}$ \\ ${ }^{1}$ Department of Surgery, VU University Medical Centre, Amsterdam, The Netherlands \\ ${ }^{2}$ Department of Clinical Biochemistry, Hotel-Dieu Hospital, AP-HP Paris, France
}

(Received 28 September 2004 - Revised 1 February 2005 - Accepted 14 February 2005)

\begin{abstract}
Enhancement of depressed plasma concentrations of glutamine and arginine is associated with better clinical outcome. Supplementation of glutamine might be a way to provide the patient with glutamine, and also arginine, because glutamine provides the kidney with citrulline, from which the kidney produces arginine when plasma levels of arginine are low. The aim of the present study was to investigate the parenteral and enteral response of the administered dipeptide Ala-Gln, glutamine, citrulline and arginine. Therefore, seven patients received $20 \mathrm{~g}$ Ala-Gln, administered over $4 \mathrm{~h}$, parenterally or enterally, on two separate occasions. Arterial blood samples were taken before and during the administration of Ala-Gln. ANOVA and a paired $t$ test were used to test differences $(P<0.05)$. Ala-Gln was undetectable with enteral administration, whereas Ala-Gln remained stable at a plasma concentration of $268 \mu m o l / 1$ throughout parenteral infusion and rapidly decreased towards zero after infusion was stopped. The highest level of glutamine was observed with parenteral infusion of the dipeptide, although enteral infusion also significantly increased plasma levels of glutamine. The highest plasma response of citrulline was observed with the enteral administration of the dipeptide, although parenteral administration also increased plasma levels of citrulline. Plasma arginine increased significantly with parenteral infusion, but not with enteral administration of Ala-Gln. In conclusion, administrations of Ala-Gln, parenteral or enteral, resulted in an increased plasma glutamine response, as compared with baseline. Interestingly, in spite of the high availability of citrulline with enteral administration of the dipeptide, only parenteral infusion of Ala-Gln increased plasma arginine concentration.
\end{abstract}

Ala-GIn: Glutamine: Citrulline: Arginine: Parenteral nutrition: Enteral nutrition

The benefit of nutritional support in critically ill patients has been the subject of extensive study in recent years. The reason is that the intensive care population has a high prevalence of disease-related malnutrition $(>40 \%)$, which is associated with an increased morbidity and mortality (Giner et al. 1996).

Next to improvement of food policy on the intensive care unit, including early, preferably enteral, feeding of an optimal dose of energy and protein, special formulas have been designed with an enrichment of certain nutrients to enhance recovery, based on their biological properties.

Within this scope, formulas enriched with the amino acids arginine and glutamine were developed. Both amino acids have been proven to enhance the immune system and improve organ function (Murphy \& Newsholme, 1998; Newsholme, 2001; Rodriguez et al. 2002; Ziegler et al. 2003).

However, arginine supplementation for the critically ill is currently under debate, because a sub-analysis within a meta-analysis of twenty-two clinical trials showed a tendency $(P=0.051)$ towards an increase in mortality in septic patients (Heyland et al. 2001). This finding was confirmed in a recent randomised multicentre trial with patients having severe sepsis (Bertolini et al. 2003). There was significantly higher mortality in patients receiving enteral arginine-enriched nutrition compared with patients receiving parenteral nutrition.

Hypothetically, supplementation of the amino acid glutamine, an indirect precursor for arginine, might be a more physiological way to generate arginine, because synthesis is regulated by the kidney, and only low levels of arginine trigger synthesis (Prins et al. 1999). The kidney is the most important organ for endogenous arginine synthesis, where it is metabolised from citrulline (Wu \& Morris, 1998). Citrulline in turn is predominantly metabolised in the intestine from either glutamine or arginine (Windmueller \& Spaeth, 1981; Cynober et al. 1995; Wu \& Morris, 1998). Houdijk et al. (1994) showed in an experimental rat model that a glutamine-enriched enteral diet increased plasma arginine concentrations by increasing renal arginine production. This finding was confirmed in a randomised clinical trial with trauma patients, who expressed a low plasma arginine concentration. A glutamine-enriched enteral feeding normalised plasma arginine concentrations within a couple of days (Houdijk et al. 1998).

The subject of the present study was the relationship between arginine and glutamine. Considering the importance of enteral glutamine metabolism in endogenous arginine synthesis, we 
investigated how the route of feeding, either parenterally or enterally, affected plasma concentrations of glutamine, citrulline and arginine. Therefore, we compared a $4 \mathrm{~h}$ continuous parenteral infusion with a $4 \mathrm{~h}$ enteral administration of the dipeptide AlaGln (Furst, 1998). Furthermore, we investigated if there was a difference between the plasma concentration of the dipeptide during parenteral or enteral supply.

\section{Patients and methods}

\section{Patients}

Seven patients undergoing liver resection for metastatic colorectal cancer in the VU University Medical Centre, Amsterdam, The Netherlands, were included in the present study. Patients between 35 and 75 years were considered eligible for the study. Exclusion criteria were pregnancy, unfitness for surgery, use of corticosteroids 4 weeks before surgery, insulin-dependent diabetes mellitus, Coeliac or Crohn's disease or another major cause of intestinal malabsorption.

Patients' characteristics are given in Table 1. The BMI of patients did not reveal malnourishment. Patients were considered to be at risk for malnourishment if BMI was $<20 \mathrm{~kg} / \mathrm{m}^{2}$ (Elia \& Lunn, 1997). All patients expressed a slightly increased level of $\gamma$-glutamyl-transferase in plasma (92 (SE 34) U/l) before the study. However, transaminases and bilirubin were not enhanced in any of the patients and, thus, liver function was considered to be normal. Furthermore, none of the patients demonstrated malfunction of the kidney, judged by plasma creatinine and urea concentrations.

Informed consent was obtained from all patients before inclusion and the study protocol was approved by the ethical committee of the VU University Medical Centre.

\section{Study design}

Patients were admitted to the hospital $3 \mathrm{~d}$ before surgery. Height and weight were recorded and BMI was calculated. Furthermore, liver enzymes and renal function were observed before the start of the study, since both organs are involved in the observed metabolism of glutamine, citrulline and arginine.

All patients received a parenteral or enteral solution of Ala-Gln (Dipeptiven ${ }^{\circledR}$; Fresenius Kabi, Bad Homburg, Germany) on two separate occasions, on two consecutive days. For the enteral route all patients received a self-propelling nasojejunal tube (Bengmark $^{\circledR}$; Nutricia, Zoetermeer, The Netherlands). The pH was measured immediately after insertion to check if the tube

Table 1. Patient characteristics

(Mean values with their standard errors)

\begin{tabular}{lrr}
\hline & Mean & SE \\
\hline Males $(n)$ & 5 & \\
Females $(n)$ & 2 & \\
Age (years) & 63 & 2 \\
Weight $(\mathrm{kg})$ & 88 & 6 \\
Height $(\mathrm{cm})$ & 177 & 6 \\
BMl $\left(\mathrm{kg} / \mathrm{m}^{2}\right)$ & 29 & 3 \\
\hline
\end{tabular}

For details of procedures, see p. 20 was properly placed in the stomach $(\mathrm{pH}<2)$ and an X-ray of the abdomen was made $1 \mathrm{~d}$ after insertion to check if the tube had migrated to the jejunum. For the parenteral route an intravenous line was placed in the forearm. Patients received the solution parenterally $2 \mathrm{~d}$ before surgery and enterally on the day before surgery. Patients received the solutions in the morning after overnight fasting. Water was allowed ad libitum. Patients were not allowed to eat or drink other beverages after 20.00 hours on the evening before the parenteral or enteral administration of AlaGln. Furthermore, coffee, tea and sleep-inducing medication were not allowed.

\section{Infusion protocol}

The continuous $4 \mathrm{~h}$ administration of $100 \mathrm{ml}$ Dipeptiven ${ }^{\circledR}$ (Fresenius Kabi) containing $20 \mathrm{~g}$ the dipeptide Ala-Gln, dissolved in $400 \mathrm{ml} 0.9 \% \mathrm{NaCl}$ was started between 08.00 and 10.00 hours, either parenterally or enterally on two separate occasions, on two consecutive days. Administration rate was $23 \mathrm{mmol}$ Ala-Gln/h. Arterial blood samples were taken before the start and at 15, 30, $45,60,90,120,180,240,250,260$ and $270 \mathrm{~min}$ after start of administration. The last three samples $(250,260,270 \mathrm{~min})$ were obtained after the solution was administered, to study the decay curve.

\section{Preparation of blood samples}

Blood was collected in heparin tubes and directly put on ice. Samples were centrifuged within $15 \mathrm{~min}$ after collection, for $10 \mathrm{~min}$ at $2000 \mathrm{~g}$ in a $4^{\circ} \mathrm{C}$ cooled centrifuge. Two portions of $500 \mu \mathrm{l}$ plasma of each sample were put in two cryovials with $20 \mathrm{mg}$ dry sulfosalicyclic acid for deproteinising, vortexed, frozen in liquid $\mathrm{N}_{2}$ and kept at $-80^{\circ} \mathrm{C}$ until analysis.

\section{Amino acid analysis}

The concentrations of free amino acids were determined using a reverse-phase HPLC as previously described (Teerlink et al. 1994). The plasma concentration of the Ala-Gln was determined using ion-exchange chromatography and spectrometric detection after ninhydrin derivatisation (Neveux et al. 2004) on an automatic analyser (Jeol Aminotac JLC-500V analyzer; Jeol, Croissy-sur-Seine, France). The manufacturer's onboard program (Physio C) was adapted to enable adequate separation of the dipeptide (J. Jonte, T. Popovici, J.P. De Bandt and L. Cynober, unpublished results).

\section{Statistical analysis}

Data are expressed as means with their standard errors. Distributions of Ala-Gln and free amino acid concentrations in samples, drawn at different points in time, were checked for normality using the Shapiro-Wilks test. Because data were normally distributed, one-way ANOVA for repeated measures was performed. If ANOVA was significant, a paired $t$ test was performed to compare means of amino acid concentrations at different points in time with baseline (sample taken before the start of administration of Ala-Gln) and to compare means of amino acid concentrations obtained during enteral or parenteral administration at the corresponding points in time, on the two consecutive days. $P<0.05$ was considered significant. SPSS 9.0 for Windows ${ }^{\circledR}$ (SPSS Inc., 
Chicago, IL, USA) was used to perform the statistical calculations.

\section{Results}

No complaints or side effects were observed during parenteral or enteral administration of Ala-Gln.

\section{Plasma dipeptide concentration}

Patients received on average 269 (SE 21) $\mu \mathrm{mol} \mathrm{Ala-Gln/h}$ per kg parenterally or enterally during $4 \mathrm{~h}$ on two separate occasions, on two consecutive days. When Ala-Gln was infused parenterally, the plasma concentration of Ala-Gln reached a concentration of 262 (SE 27) $\mu \mathrm{mol} / \mathrm{l}$ at $60 \mathrm{~min}$. Thereafter plasma concentration remained stable at an average concentration of $260 \mu \mathrm{mol} / \mathrm{l}$ throughout infusion. After finishing infusion, at $240 \mathrm{~min}$, plasma concentration of Ala-Gln rapidly decreased towards zero (Fig. 1).

Enteral administration of Ala-Gln, on the other hand, did not result in a detectable plasma concentration of Ala-Gln. This difference between the enteral and parenteral route was significant from 30 to $250 \mathrm{~min}$.

\section{Plasma glutamine concentration}

Administration of Ala-Gln resulted in a significant increase in the plasma concentration of the constituent amino acids glutamine and alanine with both parenteral and enteral administration. Baseline plasma glutamine concentrations were 585 (SE 51) $\mu \mathrm{mol} / \mathrm{l}$ (parenteral) and 581 (SE 20) $\mu \mathrm{mol} / \mathrm{l}$ (enteral) (NS). Both feeding routes resulted in a significant increment in plasma glutamine response in time. During the parenteral infusion, plasma glutamine concentrations were higher than baseline at $15 \mathrm{~min}$ and still higher at $270 \mathrm{~min}$ after start of infusion, with a peak increment of 468 (SE 57) $\mu \mathrm{mol} / 1$ at $240 \mathrm{~min}$. During the enteral administration, plasma glutamine was significantly higher than baseline from 30 to $260 \mathrm{~min}$, with a peak increment of 207 (SE 42) $\mu \mathrm{mol} / \mathrm{l}$ at $90 \mathrm{~min}$. A comparison of enteral with parenteral

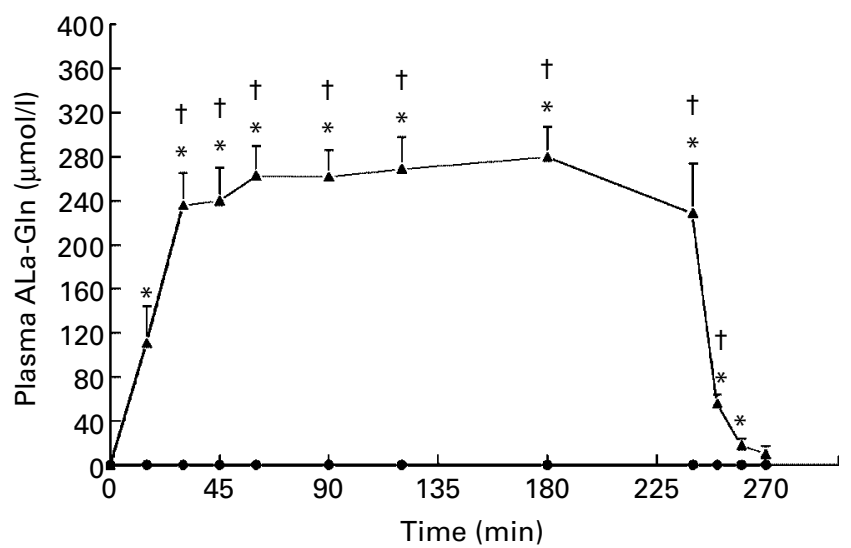

Fig. 1. Graphic illustration of plasma Ala-Gln response with parenteral (-4-) or enteral (-๑-) infusion of Ala-Gln. Mean value was significantly different from that at baseline $\left({ }^{*} P<0.05\right)$. Mean value for parenteral nutrition was significantly different from that for enteral nutrition $(\dagger P<0.05)$.

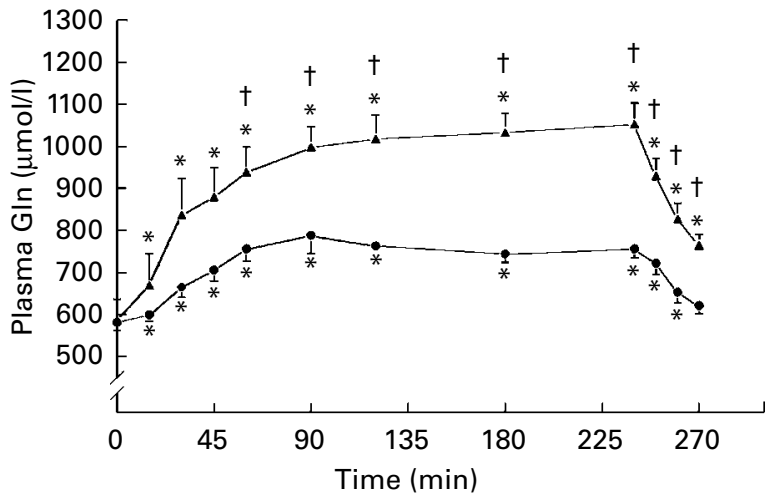

Fig. 2. Graphic illustration of plasma glutamine (Gln) response with parent-

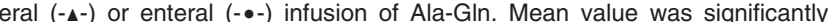
different from that at baseline $\left({ }^{\star} P<0.05\right)$. Mean value for parenteral nutrition was significantly different from that for enteral nutrition $(\dagger P<0.05)$.

administration at the corresponding points in time showed that plasma glutamine was significantly higher with parenteral infusion from 60 to 270 min (Fig. 2).

\section{Plasma glutamate concentration}

The plasma concentration of glutamate, the intermediary metabolite in the glutamine to citrulline pathway, did not change with parenteral infusion as compared with baseline. During enteral administration, plasma glutamate concentration increased significantly from 45 to $260 \mathrm{~min}$. This difference between enteral and parenteral administration was significant at 60,120 and $240 \mathrm{~min}$ (Fig. 3).

\section{Plasma citrulline concentration}

During parenteral or enteral administration of Ala-Gln, plasma citrulline concentrations were significantly higher than baseline from 45 to $260 \mathrm{~min}$. Plasma citrulline response was significantly

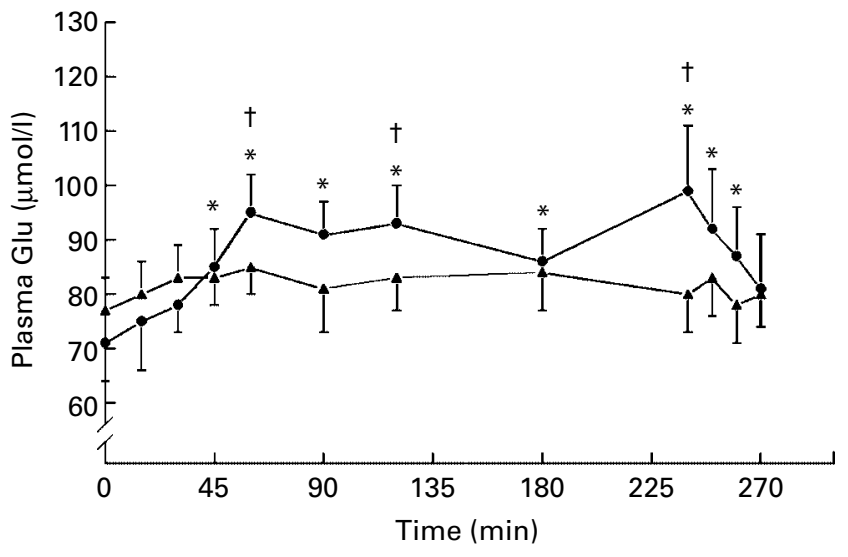

Fig. 3. Graphic illustration of plasma glutamate (Glu) response with parent-

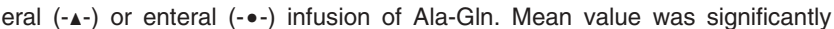
different from that at baseline ( $\left.{ }^{\star} P<0.05\right)$. Mean value for parenteral nutrition was significantly different from that for enteral nutrition $(\dagger P<0.05)$. 


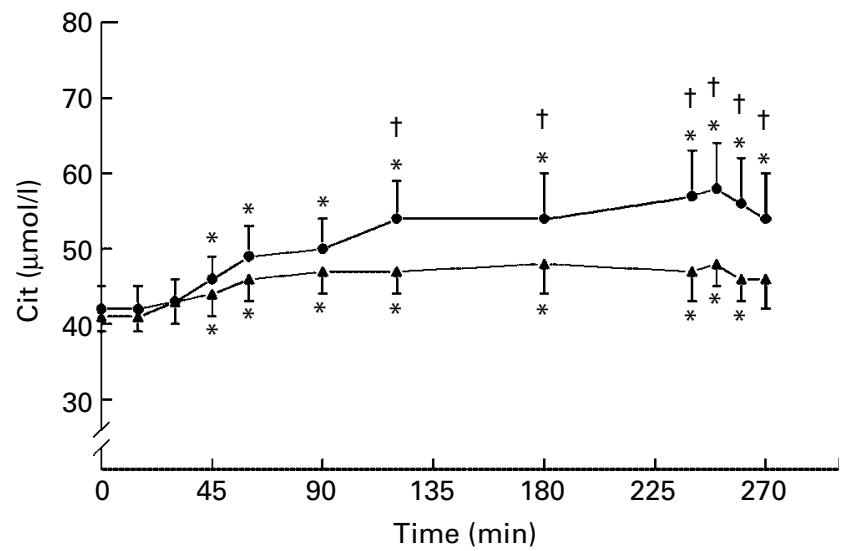

Fig. 4. Graphic illustration of plasma citrulline (Cit) response with parenteral $\left(-\mathbf{\Delta}^{-}\right)$or enteral (-๑-) infusion of Ala-GIn. Mean value was significantly different from that at baseline $\left({ }^{\star} P<0 \cdot 05\right)$. Mean value for parenteral nutrition was significantly different from that for enteral nutrition $(\dagger P<0.05)$.

higher from 120 to 270 min during enteral infusion when compared with parenteral infusion (Fig. 4).

\section{Plasma arginine concentration}

During parenteral infusion a slight but significant increment in plasma arginine response in time was observed. Plasma arginine was higher than baseline from 30 to $180 \mathrm{~min}$. A comparison of enteral with parenteral administration at the corresponding points in time did not reveal any difference (Fig. 5).

\section{Plasma concentrations of other amino acids}

Kinetics of other amino acids were studied as well (Tables 2 and 3). This resulted in some interesting observations, which are summarised later.

The plasma concentration of the non-essential amino acid taurine increased significantly with parenteral infusion of Ala-Gln. Enteral infusion of Ala-Gln did not affect plasma taurine concentration.

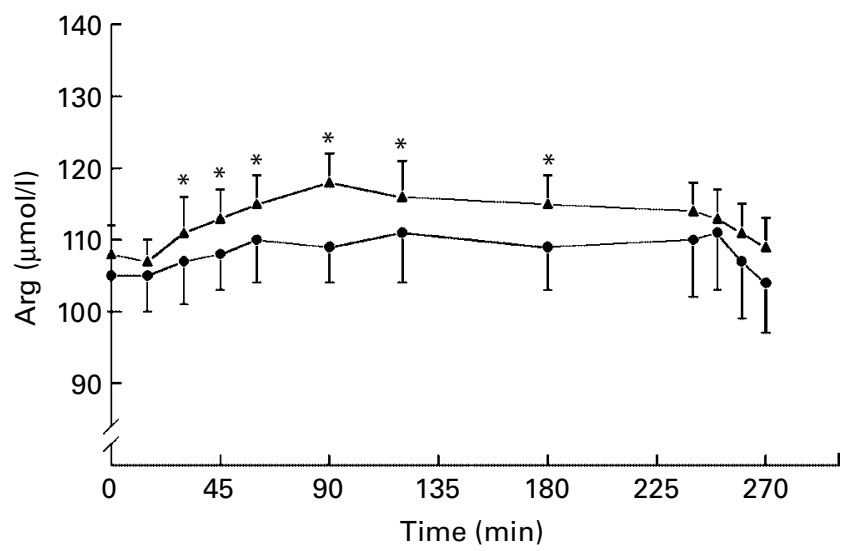

Fig. 5. Graphic illustration of plasma arginine (Arg) response with parenteral

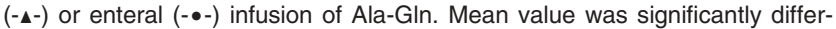
ent from that at baseline $\left({ }^{\star} P<0 \cdot 05\right)$. Mean value for parenteral nutrition was significantly different from that for enteral nutrition $(\dagger P<0.05)$.
The essential amino acids phenylalanine, isoleucine, tyrosine, valine, tryptophan and leucine and the non-essential amino acid glycine decreased with both parenteral and enteral infusion. A comparison of enteral and parenteral infusions at the corresponding points in time showed that plasma valine concentration decreased more during parenteral infusion than during enteral infusion.

\section{Discussion}

The goal of the present study was to investigate the plasma response of glutamine, citrulline and arginine to parenteral or enteral supply of Ala-Gln. Importantly, we found that both feeding routes increased plasma concentrations of glutamine and citrulline to a different extent and that plasma arginine concentration only increased with parenteral infusion of Ala-Gln. These results show that the metabolic pathway from glutamine to citrulline and arginine is affected by the feeding route. This suggests that the choice of how to feed patients - enterally or parenterally also needs to be based on the metabolic effect of either route. The chronological order of the metabolic pathway from glutamine to arginine, starting with the metabolic handling of the dipeptide, will be followed in the discussion of the results and their relevance for the clinical practice.

Ala-Gln is a practical way to provide glutamine parenterally (Albers et al. 1988, 1989; Hubl et al. 1989; Lochs et al. 1990). Not much is known about the fate of enterally supplied AlaGln. The present study proved that glutamine derived from enterally supplied Ala-Gln reaches the systemic circulation, although the plasma response of glutamine was more pronounced with parenteral administration. Enterally supplied Ala-Gln was completely hydrolysed, which was demonstrated by the undetectable low concentration of the dipeptide. This is an observation that has not been described before. However, absorption and subsequent hydrolysis of dipeptides has been studied extensively in the past. Therefore, enterally supplied Ala-Gln was most probably either hydrolysed on the surface of the intestinal mucosal cell or taken up in one piece, followed by intracellular hydrolysis or by hydrolysis in the liver (Silk, 1974; Minami et al. 1992). In contrast, Ala-Gln was detectable in plasma during parenteral infusion. Patients received on average 269 (SE 21) $\mu \mathrm{mol}$ Ala-Gln/h per $\mathrm{kg}$, a rate of infusion higher than in other studies. For instance, Lochs et al. (1990) infused $100 \mu \mathrm{mol} / \mathrm{h}$ per $\mathrm{kg}$ and Albers et al. (1989) $110 \mu \mathrm{mol} / \mathrm{h}$ per $\mathrm{kg}$ parenterally. This might explain the difference between the level of Ala-Gln at steady state during parenteral infusion in the present study, when compared with the levels in these other studies: the plasma concentration of Ala-Gln remained stable at an average concentration of $268 \mu \mathrm{mol} / 1$ in the present study, while Lochs et al. (1990) observed a steady state at $70 \mu \mathrm{mol} / \mathrm{l}$ and Albers et al. (1989) at $50 \mu \mathrm{mol} / \mathrm{l}$, during continuous parenteral infusion. Anyhow, the steady state and the rapid decrease of levels of Ala-Gln towards zero, after infusion was finished, showed that parenterally infused Ala-Gln did not accumulate in the body.

A large part of glutamine derived from the enterally administered Ala-Gln was probably metabolised in the splanchnic area, which can be suggested from the lower plasma glutamine response to enteral administration. This might be explained by the importance of glutamine as a major fuel and nucleotide substrate for the gut and the gut-associated immune system (Scheppach et al. 
Plasma amino acid response altered by route

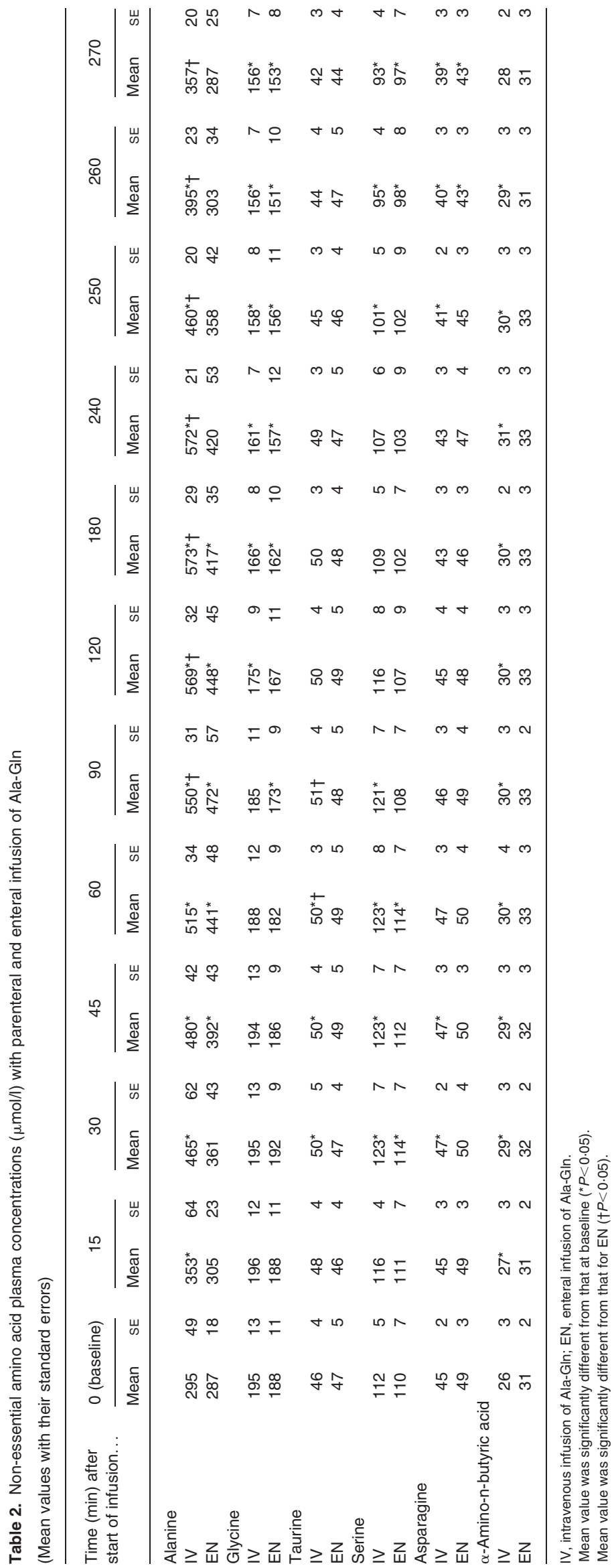


G. C. Melis et al.

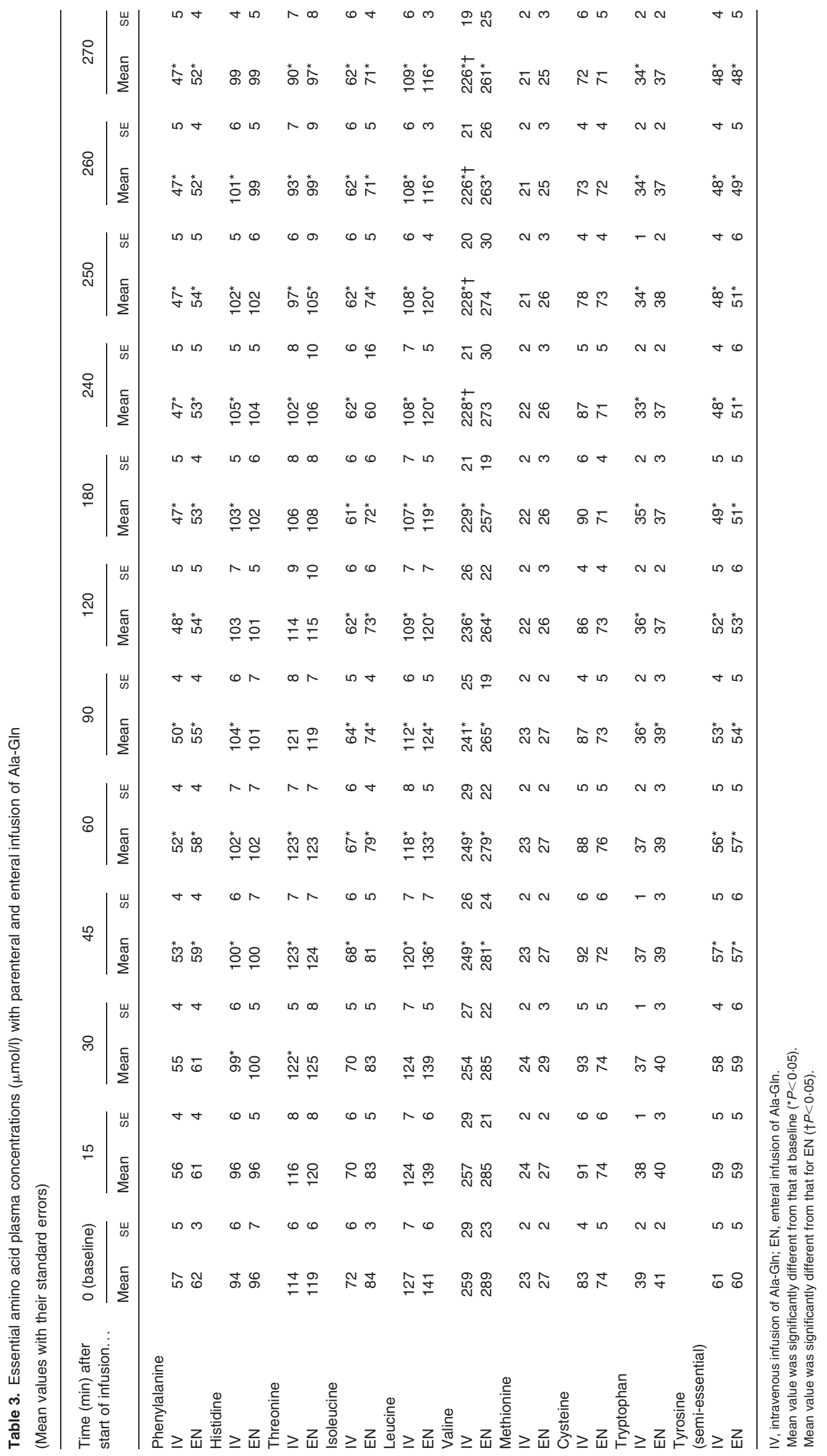


1994; McCauley et al. 1998; Wiren et al. 1998). Previous studies have shown that the total splanchnic use of enterally supplied glutamine is likely to represent $50-70 \%$ of glutamine load (Darmaun et al. 1986; Matthews et al. 1993). Also, glutamine is used for gluconeogenesis by the liver in the fasting state (Souba, 1992) and was likely to be used by the tumour in the patients studied here (Souba, 1992; Dudrick et al. 1993; Espat et al. 1995). It is not clear how much glutamine was used by the tumour in these patients. Ridge et al. (1987) have described how colorectal metastasis extracts as much glutamine as a comparable amount of liver tissue when glutamine is provided by the hepatic artery. Furthermore, they described that less glutamine is extracted when glutamine is offered by the portal vein, which was the case in the present study by the enteral route. In the present study, baseline values of glutamine were within the range of what is considered to be normal and levels of glutamine were largely elevated with parenteral administration of glutamine, despite the positive uptake in the tumour. We therefore estimate the uptake by the tumour to be small. The metabolism of enterally supplied glutamine in the splanchnic area was furthermore reflected by the plasma response of glutamate and citrulline. Glutamate increased with the enteral but not with the parenteral route of administration. This increment in the plasma glutamate concentration might contribute to the beneficial effect of enterally supplied glutamine on gut integrity (van der Hulst et al. 1993), because deamidation of glutamine into glutamate is required to reduce the paracellular permeability of the gut mucosa (Le Bacquer et al. 2003). The finding that glutamine is largely metabolised in the splanchnic area suggests that in case of severe depression of the glutamine content in blood, enteral supplementation might need to be combined with parenteral supplementation of glutamine, in order to have more than a local effect on the permeability of the intestine and the gut surrounding the immune system.

As for citrulline, the results from the present study indicate that enterally supplied glutamine serves indeed as a precursor for citrulline in the intestine. Despite the more pronounced increase in levels of citrulline with enterally supplied Ala-Gln, arginine levels did not increase with enteral supply of Ala-Gln. In contrast, despite the lower plasma response of citrulline, plasma levels of arginine did increase with parenteral supply of Ala-Gln. Houdijk et al. (1998) showed that glutamineenriched enteral nutrition normalised plasma arginine concentration in trauma patients with low plasma arginine levels at the onset of the trial (56 (SD 25) $\mu \mathrm{mol} / \mathrm{l})$. Patients from the present study expressed already slightly elevated plasma concentrations of arginine (105 (SE 11) $\mu \mathrm{mol} / \mathrm{l})$ at the start of the study. Therefore, plasma arginine concentrations were not likely to trigger arginine production from citrulline by the kidney. This result suggests that the enteral route might be preferable to the parenteral route in critically ill patients. However, the present study does not prove that the parenterally provided glutamine was converted into arginine. To elucidate this, a study design involving stable isotopes is required.

As for the other amino acids, a slight but significant increase in plasma concentrations of taurine was observed during parenteral infusion. Glutamine might be regulative in taurine metabolism, because Boelens et al. (2003) observed an increase in plasma taurine concentrations in trauma patients who received glutamine-enriched enteral nutrition. However, the relationship between glutamine and taurine remains to be elucidated, and is likely to be different under circumstances of critical illness.
Almost all concentrations of essential amino acids decreased with both administrations of Ala-Gln. This is most certainly due to the restriction of a normal diet for $16 \mathrm{~h}$, since essential amino acids need to be ingested by nutrition.

In conclusion, interesting differences were observed in plasma responses of glutamine, citrulline and arginine to parenteral or enteral administration of Ala-Gln in preoperative patients, suggesting that the choice of feeding route results in different metabolic handling of glutamine. Important is that both enteral and parenteral administration of Ala-Gln resulted in a higher plasma glutamine concentration, which suggests that enteral supply of Ala-Gln might be useful in clinical practice.

The splanchnic metabolism of enterally supplied Ala-Gln was suggested by the absence of Ala-Gln in plasma, less pronounced increase in plasma concentrations of glutamine and more pronounced increase in plasma concentrations of glutamate and citrulline with enteral administration, as compared with parenteral infusion. Splanchnic metabolism of glutamine might contribute to the beneficial effects of glutamine-enriched enteral nutrition on gut integrity. Since critically ill patients are more prone to infections, this might be a reason to provide at least a part of the supplementary glutamine by the enteral route.

Furthermore, parenteral infusion of Ala-Gln increased the plasma arginine concentration, whereas enteral supply did not increase plasma arginine levels, despite an abundance of citrulline. Further exploration of the observed differences is warranted, considering the concern about possible harmful side effects of arginine. Within this scope, it might be necessary to investigate the pathway from glutamine to arginine with the help of stable isotopes.

\section{Acknowledgements}

P. B. is a recipient of a fellowship of the Dutch Council for Medical Research of the Netherlands Organisation of Scientific Research. The authors would like to thank S. de Jong from the department of clinical biochemistry of the VU University Medical Centre for the determination of the plasma concentrations of free amino acids.

\section{References}

Albers S, Wernerman J, Stehle P, Vinnars E \& Furst P (1988) Availability of amino acids supplied intravenously in healthy man as synthetic dipeptides: kinetic evaluation of L-alanyl-L-glutamine and glycyl-Ltyrosine. Clin Sci 75, 463-468.

Albers S, Wernerman J, Stehle P, Vinnars E \& Furst P (1989) Availability of amino acids supplied by constant intravenous infusion of synthetic dipeptides in healthy man. Clin Sci 76, 643-648.

Bertolini G, Iapichino G, Radrizzani D, Facchini R, Simini B, Bruzzone P, Zanforlin G \& Tognoni G (2003) Early enteral immunonutrition in patients with severe sepsis: results of an interim analysis of a randomized multicentre clinical trial. Intensive Care Med 29, 834-840.

Boelens PG, Houdijk AP, de Thouars HN, Teerlink T, van Engeland MI, Haarman HJ \& van Leeuwen PA (2003) Plasma taurine concentrations increase after enteral glutamine supplementation in trauma patients and stressed rats. Am J Clin Nutr 77, 250-256.

Cynober L, Le Boucher J \& Vasson MP (1995) Arginine metabolism in mammals. J Nutr Biochem 6, 402-413.

Darmaun D, Matthews DE \& Bier DM (1986) Glutamine and glutamate kinetics in humans. Am J Physiol 251, E117-E126. 
Dudrick PS, Inoue Y, Espat NJ \& Souba WW (1993) Na(+)-dependent glutamine transport in the liver of tumour-bearing rats. Surg Oncol 2, $205-215$.

Elia M \& Lunn PG (1997) Biological markers of protein-energy malnutrition. Clin Nutr 16, Suppl. 1, 11-17.

Espat NJ, Bode BP, Lind DS, Copeland EM \& Souba WW (1995) Normalization of tumor-induced increases in hepatic amino acid transport after surgical resection. Ann Surg 221, 50-58.

Furst P (1998) Old and new substrates in clinical nutrition. J Nutr 128, 789-796.

Giner M, Laviano A, Meguid MM \& Gleason JR (1996) In 1995 a correlation between malnutrition and poor outcome in critically ill patients still exists. Nutrition 12, 23-29.

Heyland DK, Novak F, Drover JW, Jain M, Su X \& Suchner U (2001) Should immunonutrition become routine in critically ill patients? A systematic review of the evidence. JAMA 286, 944-953.

Houdijk AP, Rijnsburger ER, Jansen J, Wesdorp RIC, Welss JK, McCamish MA, Teerling T, Meuwissen SGM, Haarman JThM \& van Leeuwen PAM (1998) Randomised trial of glutamine-enriched enteral nutrition on infectious morbidity in patients with multiple trauma. Lancet 352, $772-776$.

Houdijk AP, van Leeuwen PA, Teerlink T, Flinkerbusch EL, Boermeester MA, Sauerwein HP \& Wesdorp RIC (1994) Glutamine-enriched enteral diet increases renal arginine production. JPEN 18, 422-426.

Hubl W, Druml W, Langer K \& Lochs H (1989) Influence of molecular structure and plasma hydrolysis on the metabolism of glutamine-containing dipeptides in humans. Metabolism 38, Suppl. 1, 59-62.

Le Bacquer O, Laboisse C \& Darmaun D (2003) Glutamine preserves protein synthesis and paracellular permeability in Caco-2 cells submitted to 'luminal fasting'. Am J Physiol 285, G128-G136.

Lochs H, Roth E, Gasic S, Hubl W, Morse EL \& Adibi SA (1990) Splanchnic, renal, and muscle clearance of alanylglutamine in man and organ fluxes of alanine and glutamine when infused in free and peptide forms. Metabolism 39, 833-836.

McCauley R, Kong SE \& Hall J (1998) Glutamine and nucleotide metabolism within enterocytes. JPEN 22, 105-111.

Matthews DE, Marano MA \& Campbell RG (1993) Splanchnic bed utilization of glutamine and glutamic acid in humans. Am J Physiol 264, E848-E854.

Minami H, Morse EL \& Adibi SA (1992) Characteristics and mechanism of glutamine-dipeptide absorption in human intestine. Gastroenterology 103, 3-11.

Murphy C \& Newsholme P (1998) Importance of glutamine metabolism in murine macrophages and human monocytes to L-arginine biosynthesis and rates of nitrite or urea production. Clin Sci 95, 397-407.

Neveux N, David D \& Cynober L (2004) Measurement of amino acid concentrations in biological fluids and tissues using ion exchange chromatography. In Metabolic and Therapeutic Aspects of Amino Acids in Clinical Nutrition, 2nd ed., pp. 17-28 [L Cynober, editor]. Boca Raton, FL: CRC Press.

Newsholme P (2001) Why is L-glutamine metabolism important to cells of the immune system in health, postinjury, surgery or infection? J Nutr 131, 2515S-2522S.

Prins HA, Houdijk AP, Wiezer MJ, Teerlink T, van Lambalgen AA, Thijs LG \& van Leeuwen PA (1999) Reduced arginine plasma levels are the drive for arginine production by the kidney in the rat. Shock 11, 199-204.

Ridge JA, Bading JR, Gelbard AS, Benua RS \& Daly JM (1987) Perfusion of colorectal hepatic metastasis: relative distribution from the hepatic artery and portal vein. Cancer 59, 1547-1553.

Rodriguez PC, Zea AH, Culotta KS, Zabaleta J, Ochoa JB \& Ochoa AC (2002) Regulation of $\mathrm{T}$ cell receptor CD3zeta chain expression by L-arginine. J Biol Chem 277, 21123-21129.

Scheppach W, Loges C, Bartram P, Christl SU, Richter F, Dusel G, Stehele P, Fuerst P \& Kasper H (1994) Effect of free glutamine and alanyl-glutamine dipeptide on mucosal proliferation of the human ileum and colon. Gastroenterology 107, 429-434.

Silk DB (1974) Progress report. Peptide absorption in man. Gut 5, 494-501.

Souba WW (1992) Glutamine: Physiology, Biochemistry and Nutrition in Critical Illness. Austin, TX: RG Landes.

Teerlink T, van Leeuwen PA \& Houdijk A (1994) Plasma amino acids determined by liquid chromatography within 17 minutes. Clin Chem 40, 245-249.

van der Hulst RR, van Kreel BK, von Meyenfeldt MF, Brummer RJ, Arends JW, Deutz NE \& Soeters PB (1993) Glutamine and the preservation of gut integrity. Lancet 341, 1363-1365.

Windmueller HG \& Spaeth AE (1981) Source and fate of circulating citrulline. Am J Physiol 241, E473-E480.

Wiren M, Magnusson KE \& Larsson J (1998) The role of glutamine, serum and energy factors in growth of enterocyte-like cell lines. Int $J$ Biochem Cell Biol 30, 1331-1336.

Wu G \& Morris SM Jr (1998) Arginine metabolism: nitric oxide and beyond. Biochem J 336, 1-17.

Ziegler TR, Evans ME, Fernandez-Estivariz C \& Jones DP (2003) Trophic and cytoprotective nutrition for intestinal adaptation, mucosal repair, and barrier function. Annu Rev Nutr 23, 229-261. 